\title{
Resource limitation alters the $3 / 4$ size scaling of metabolic rates in phytoplankton
}

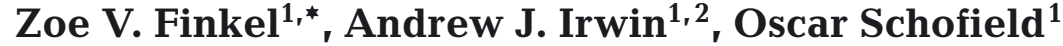 \\ ${ }^{1}$ Institute of Marine \& Coastal Sciences, Coastal Ocean Observation Laboratory, Rutgers University, \\ New Brunswick, New Jersey 08901, USA \\ ${ }^{2}$ Biology Department, College of Staten Island, City University of New York, 2800 Victory Blvd, Staten Island, \\ New York 10314, USA
}

\begin{abstract}
Under optimal growth conditions, many metabolic rates scale to the $3 / 4$ power of mass. We show that resource limitation can alter this size scaling of metabolic rates if resource acquisition depends on organism size. A prime example of size-dependent resource acquisition is light harvesting by phytoplankton. The size-dependence of light acquisition causes a deviation in the $3 / 4$ size scaling of growth and photosynthetic rates under growth-limiting irradiance. The degree of deviation from the $3 / 4$ size-scaling exponent depends on the size-dependence of physiological acclimation in response to resource limitation. Phytoplankton acclimate to light limitation by changes in pigment concentration. We calculate the pigment concentration required to maximize photosynthetic rate, and predict that the light-limited photosynthetic rate must scale to the $2 / 3$ power of cell volume. These theoretical results are consistent with the size scaling of pigment concentration and photosynthetic rate of phytoplankton cultures. Our results suggest that deviation from the $3 / 4$ size-scaling exponent for metabolic rate under resource-limiting conditions is the consequence of the size-dependence of both resource acquisition and physiological acclimation to resource availability.
\end{abstract}

KEY WORDS: 3/4 rule · Allometry $\cdot$ Light absorption · Macroecology $\cdot$ Nutrient uptake $\cdot$ Phytoplankton · Resource limitation · Size scaling

Resale or republication not permitted without written consent of the publisher

\section{INTRODUCTION}

Macroecology is the study of the emergent statistical properties of complex ecological systems (Brown 1995). Many fundamental macroecological patterns, such as abundance and diversity, have been related to organism size (Gould 1966, Peters 1983, Bonner 1988, Brown 1995, Kerr \& Dickie 2001, Trammer 2002). These patterns, in part, reflect the relationship between an organism's size and its metabolic rate (Peters 1983, Brown 1995). From bacteria to large mammals, body size $(V)$ can be used to predict metabolic rate $(M)$ :

$$
M=k\left(\frac{V}{V_{0}}\right)^{b}
$$

where $k$ is metabolic rate at reference size, and $b$ is the size-scaling exponent of the power-law dependence of
$M$ on $V / V_{0}$. Metabolic rate most commonly refers to growth or respiratory rate but can include any anabolic or catabolic rate. Organism size can be quantified as total body mass, as estimated by total carbon or dry weight, or as cell volume for microbes (Montagnes et al. 1994). Regardless of the proxy used for body size, normalizing organism size to a reference size, $V_{0}$, is necessary to keep the dimensions consistent with metabolic rate as defined in Eq. (1). Related organisms often have similar values of $k$ but it can be quite variable between taxonomically distinct groups (Chisholm 1992). In contrast, under optimal growth conditions, $b$ for the organism's metabolic rate is so frequently $3 / 4$ that it is referred to as the $3 / 4$ rule (Kleiber 1947, Peters 1983, West et al. 1997).

Recent work suggests that this $3 / 4$ rule for metabolic rates is a consequence of the geometric scaling proper- 
ties of transport networks (West et al. 1997, Banavar et al. 2002). West et al. (1997) argued that fractal transport networks regulate metabolic rates with a maximum possible size-scaling exponent of $3 / 4$. They observed that many biological surfaces are effectively fractal and thus have non-Euclidean scaling. They modify a surface-rule argument to obtain a scaling exponent of $3 / 4$ instead of $2 / 3$. Banavar et al. (2002) show that an efficient Euclidean resource delivery network which allows metabolic rate to be independent of organism size must itself scale as $V^{4 / 3}$. In many organisms, the transport network is an approximately constant proportion of body mass, and thus the metabolic rate scales to the $3 / 4$ power of body volume or mass (Banavar et al. 2002).

However, every rule has exceptions. Deviations in the size-scaling exponent have been associated with sub-optimal environmental conditions, such as extremes in temperature and irradiance (Schlesinger et al. 1981, Peters 1983, Sommer 1989, Finkel 2001, Gillooly et al. 2001). Theoretical models based on geometric scaling properties of transport networks suggest that imbalances in supply and demand could cause deviations from the $3 / 4$ rule (Banavar et al. 2002). Under resource limitation, the supply of energy and nutrients does not match the demands of growth rate. There is at present no theoretical description of how resource limitation will alter the size scaling of metabolic rates.

Under optimal environmental conditions, the energy required to acquire resources is at a minimum, and organisms can maximize the conversion of resources into growth and reproduction. Under these optimal growth conditions, the maximum intrinsic growth rate is obtained, and the $3 / 4$ size scaling of metabolism is often achieved (Kleiber 1961, Peters 1983). As the environmental conditions depart from optimal conditions, resources become more difficult to obtain, resulting in a decreased growth rate. In order to maximize the efficiency of resource acquisition in a variable environment, cellular physiology adjusts through a suite of acclimation processes (Morris \& Glover 1974, Jones 1978, Berry \& Bjorkman 1980, Falkowski \& LaRoche 1991, Evans \& Poorter 2001). The cost of acclimation combined with the degree to which resources are limiting is dependent on body size (Raven 1984, Agustí 1991, Hudson \& Morel 1993). This, in turn, alters the size-scaling exponent associated with metabolic rate. A quantitative understanding of how resource limitation will alter the size scaling of metabolic rates increases the general applicability of the $3 / 4$ rule by reconciling some of the discrepancies between experimental and field data and theoretical models.

We use light-limited phytoplankton as a model system to assess resource driven deviations from the $3 / 4$ rule. Phytoplankton are ideal experimental organ- isms for allometric studies due to their extremely large size range: $\sim 1 \mu \mathrm{m}$ to several millimeters in diameter (Round et al. 1990, Raven \& Kubler 2002). Phytoplankton metabolic rates are central to the global biogeochemical cycles of carbon, nitrogen, oxygen, silicon, phosphorus and iron, and account for $40 \%$ of global primary production (Falkowski 1994). We focus on light limitation as the limiting resource for 3 reasons: (1) there is a mature physical theory that describes light acquisition in cells (Kirk 1976, Morel \& Bricaud 1981); (2) there are well-tested, mechanistic, quantitative models of light harvesting and growth as a function of irradiance; and (3) the growth rate of a majority of the phytoplankton cells in the oceans is limited by light (Cullen et al. 1982). Nutrients such as nitrate, phosphate and iron are also known to limit primary production in the ocean. We chose not to explicitly model the effect of nutrient limitation on the size scaling of metabolic rate because there is much less data on how the different nutrient uptake systems respond to changes in nutrient concentration and how this influences the size-dependence of nutrient uptake.

Here, we develop a physiologically based mechanistic model to explain how disequilibria between supply and demand for light can alter the $3 / 4$ size scaling of metabolic rates. Our objectives are to calculate how physiological acclimation to light limitation leads to altered cellular composition and the anomalous size scaling of photosynthesis in unicellular phytoplankton. We use a biophysical model of light absorption to determine the cellular chlorophyll concentration that maximizes photosynthesis for cells of different sizes. This permits us to calculate the size-dependence of photosynthesis as a function of irradiance. Model results are compared with experimental data, testing our hypothesis that resource limitation can alter the $3 / 4$ size scaling of metabolic rates.

\section{METHODS}

We assume that natural selection acts to maximize the cell division rate of the individual cell. Over large size-ranges and within taxonomically similar groups, under optimal experimental growth conditions, evidence suggests that growth rate is a function of the internal transport network and is described by the $3 / 4$ rule (Eq. 1; Hemmingsen 1960, Kleiber 1961, Peters 1983, West et al. 1997, Banavar et al. 2002). Under light limitation, growth rate is limited by the acquisition of photons. Below, we describe the photosynthetic response to varying irradiance as a function of cell size and show how an optimal light-harvesting strategy can be used to predict the change in size scaling of photosynthetic rate with resource supply. 
Table 1. List of symbols

\begin{tabular}{|c|c|c|c|c|}
\hline Symbol & Definition and examples & $\begin{array}{l}\text { Input variables, and } \\
\text { typical range of values }\end{array}$ & Units & Source \\
\hline a & $\begin{array}{l}\text { Cellular optical absorption } \\
\text { cross-section }\end{array}$ & $10^{-13}$ to $10^{-9}$ & $\mathrm{~m}^{2} \operatorname{cell}^{-1}$ & $\begin{array}{l}\text { Agustí (1991), } \\
\text { Finkel (2001) }\end{array}$ \\
\hline$a^{*}$ & $\begin{array}{l}\text { Chl a specific optical absorption } \\
\text { cross-section }\end{array}$ & 0.01 to 0.02 & $\mathrm{~m}^{2} \mathrm{mg} \mathrm{chl} a^{-1}$ & $\begin{array}{l}\text { Agustí (1991), } \\
\text { Finkel (2001) }\end{array}$ \\
\hline$a^{*}{ }_{\mathrm{S}}$ & In vitro $a^{*}$ (unpackaged) & 0.02 to 0.04 & $\mathrm{~m}^{2} \mathrm{mg} \mathrm{chl} \mathrm{a}{ }^{-1}$ & Morel \& Bricaud (1981) \\
\hline$\alpha$ & Photosynthetic efficiency & & $\mathrm{mg} \mathrm{C}$ cell $^{-1} \mu \mathrm{E}^{-1} \mathrm{~m}^{2}$ & \\
\hline$B$ & Benefit of the LHC & & $\mathrm{mg} \mathrm{C}$ cell $^{-1} \mathrm{~h}^{-1}$ & \\
\hline$B_{\mathrm{L}}$ & $\begin{array}{l}\text { Benefit of the LHC under } \\
\text { light limitation }\end{array}$ & & $\mathrm{mg} \mathrm{C}$ cell $^{-1} \mathrm{~h}^{-1}$ & \\
\hline$b$ & Size-scaling exponent & & Dimensionless & \\
\hline$C$ & Cost of the LHC & & $\mathrm{mg} \mathrm{C}$ cell $^{-1} \mathrm{~h}^{-1}$ & \\
\hline$C_{\mathrm{i}}$ & Intracellular chl a concentration & $10^{5}$ to $10^{8}$ & $\mathrm{mg} \operatorname{chl} a \mathrm{~m}^{-3}$ & Agustí (1991) \\
\hline$d$ & Cell diameter & $10^{-6}$ to $10^{-3}$ & $\mathrm{~m}$ & \\
\hline$E$ & Growth irradiance & $10^{-6}$ to $2 \times 10^{-3}$ & mol photons $\mathrm{m}^{-2} \mathrm{~s}^{-1}$ & \\
\hline$E_{\mathrm{k}}$ & $P_{\max } / \alpha$ & & $\mu E \mathrm{~m}^{-1} \mathrm{~s}^{-1}$ & \\
\hline$k$ & Metabolic rate at reference size & & $\mathrm{h}^{-1}$ & \\
\hline$k_{P_{\max }}$ & $\begin{array}{l}\text { Maximum photosynthetic rate } \\
\text { per cell at reference size }\end{array}$ & $10^{-9.95}$ & $\mathrm{mg} \mathrm{C}$ cell $^{-1} \mathrm{~h}^{-1}$ & Finkel (2001) \\
\hline$M$ & $\begin{array}{l}\text { Metabolic rate; net photosynthetic } \\
\text { rate, specific growth rate, etc. }\end{array}$ & & $\mathrm{h}^{-1}$ & \\
\hline$N$ & $\begin{array}{l}\text { Net benefit, net number of photons } \\
\text { harvested resulting in carbon fixed }\end{array}$ & & $\mathrm{mg} \mathrm{C}$ cell $^{-1} \mathrm{~s}^{-1}$ & \\
\hline$P$ & Photosynthetic rate per cell & & $\mathrm{mg} \mathrm{C}$ cell $^{-1} \mathrm{~h}^{-1}$ & \\
\hline$P_{\max }$ & Maximum photosynthetic rate per cell & & $\mathrm{mg} \mathrm{C}$ cell $^{-1} \mathrm{~h}^{-1}$ & \\
\hline$\tau$ & $\begin{array}{l}\text { Average lifetime of the LHC over } \\
\text { which the cost of the LHC is amortized }\end{array}$ & $\sim 24$ & $\mathrm{~h}$ & Riper et al. (1979) \\
\hline$\phi$ & Quantum yield of photosynthesis & 0.1 & mol C mol photons ${ }^{-1}$ & Kirk (1994) \\
\hline$V$ & $\begin{array}{l}\text { Organism size. Can use estimates } \\
\text { of cell volume or biomass }\end{array}$ & & $\mathrm{m}^{3}$ & \\
\hline$\xi$ & $\begin{array}{l}\text { Cost of the LHC } \\
\text { (upper estimate for chl a) }\end{array}$ & $7 \times 10^{-4}$ & mol photons mg chl $a^{-1}$ & Raven (1984) \\
\hline
\end{tabular}

Steady-state photosynthesis as a function of irradiance. The relationship between irradiance and photosynthetic rate $(P)$ is commonly expressed as an exponential or hyperbolic tangent function of irradiance $(E)$ :

$$
P(E)=P_{\max } \times \tanh \left(\text { a } \phi E / P_{\max }\right)
$$

where $a$ is the cellular absorption cross-section weighted to the spectral irradiance; $\phi$, the quantum yield of photosynthesis, is a saturating function of the maximum quantum yield $\left(\phi_{\mathrm{m}}\right)$ and irradiance (Welschmeyer \& Lorenzen 1981); and $P_{\max }$ is the maximum photosynthetic rate (see Table 1 for a list of symbols, their units, and typical values). As E increases from zero, $P$ increases approximately linearly with $E$. The slope of $P$ versus $E$, as $E \rightarrow 0$, is referred to as $\alpha$, or photosynthetic efficiency. When irradiances become saturating (at $E_{\mathrm{k}}=P_{\mathrm{max}} / \alpha$ ), photosynthesis is close to its maximum rate $\left(P_{\max }\right)$, and there is very little increase in photosyn- thetic rate with irradiance. Although size-dependence has been reported for $P_{\max }$ and $\alpha$ (Taguchi 1976, Finkel 2001), the size scaling of photosynthesis has generally not been explicitly considered in models of photosynthesis (Cullen et al. 1993).

Steady-state size scaling of photosynthesis under light-limiting conditions. Under light-limiting conditions photosynthetic rate is proportional to $\alpha \phi E$. For cells grown at irradiances below $E_{\mathrm{k}}$, quantum yield is at its maximum, and here is assumed to be $0.1 \mathrm{~mol} \mathrm{C} \mathrm{mol} \mathrm{pho-}$ tons $^{-1}$ (Kirk 1994). For simplicity, we assign $\phi$ a value of $0.1 \mathrm{~mol} \mathrm{C} \mathrm{mol} \mathrm{photons}^{-1}$ for all E. Light absorption is much more variable. It is a function of pigment composition, pigment concentration and cell size. Following Morel \& Bricaud (1981), light absorption for a spherical cell can be approximated as:

$$
a=a^{*} c_{\mathrm{i}} V
$$


where $c_{\mathrm{i}}$ is the intracellular chl a concentration (mg chl $\left.a \mathrm{~m}^{-3}\right)$, and $a^{*}$ is the chl a specific absorption crosssection $\left(\mathrm{m}^{2} \mathrm{mg} \mathrm{chl} \mathrm{a}^{-1}\right)$, which is equal to:

$$
a^{*}=\frac{3}{2} a^{*} \frac{Q(\rho)}{\rho}
$$

where $a^{*}{ }_{s}$ is the absorption coefficient of the cell's pigments in solution $\left(\mathrm{m}^{2} \mathrm{mg} \mathrm{chl} \mathrm{a}^{-1}\right)$ normalized to $\mathrm{chl} a_{\text {, }}$ and:

where

$$
Q(\rho)=1+2 \mathrm{e}^{-\rho} / \rho+2\left(\mathrm{e}^{-\rho}-1\right) / \rho^{2}
$$

$$
\rho=a^{*}{ }_{\mathrm{s}} C_{\mathrm{i}} d
$$

and $d$ is cell diameter. For modeling purposes we use an estimate of $0.04 \mathrm{~m}^{2} \mathrm{mg}$ chl $a^{-1}$ for the spectrally averaged in vitro absorption coefficient of cellular pigment from Morel \& Bricaud (1981).

The ratio $a^{*}: a^{*}{ }_{s}$ is known as the package effect because as the cell (or package) gets bigger, the specific optical absorption cross-section decreases. This has been established both theoretically and empirically. Internal geometry such as the packaging of pigments into chloroplasts (Berner et al. 1989) and the optical properties of vacuoles (Raven 1997) can also alter the light absorptive properties of photosynthetic cells, but for simplicity these details will not be included in this analysis.

Steady-state size scaling of photosynthesis under light-saturating conditions. We integrate allometry into our resource-based model by defining $P_{\max }$, the maximum cellular metabolic rate by a function similar to $M$ in Eq. (1), with a size-scaling exponent of $3 / 4$ :

$$
P_{\max }=k_{P_{\max }}\left(\frac{V}{V_{0}}\right)^{3 / 4}
$$

The intercept, $k_{P_{\max }}$ is specific to the taxonomic group and steady-state growth irradiance (Finkel 2001). Under light-saturating conditions, photosynthesis $(P)$ will scale with cell volume with an exponent of $3 / 4$, while under light limitation the size-scaling exponent associated with photosynthesis is dictated by light absorption. This formulation is consistent with the 2 potential rate-limiting processes: (1) the metabolic rate based on the acquisition of resources under light-limiting conditions $\left(M_{\mathrm{R}}\right)$; and (2) the transport and metabolic consumption of those internal resources under light-saturating conditions $\left(M_{\mathrm{T}}\right)$ (Fig. 1).

Under steady-state conditions, the overall photosynthetic rate will be determined by the slower of these 2 processes: $M=\min \left(M_{\mathrm{R}}, M_{\mathrm{T}}\right.$ ) (Fig. 1). Resource acquisition depends on external resource supply (e.g. irradiance or nutrient flux), the fraction of internal resources allocated to the resource acquisition system (e.g. light harvesting complexes [LHCs], or enzymes and nutrient transporters), and the organism's size. In the case of light acquisition in unicellular phytoplankton, the rate of photon capture depends on total intracellular pig-

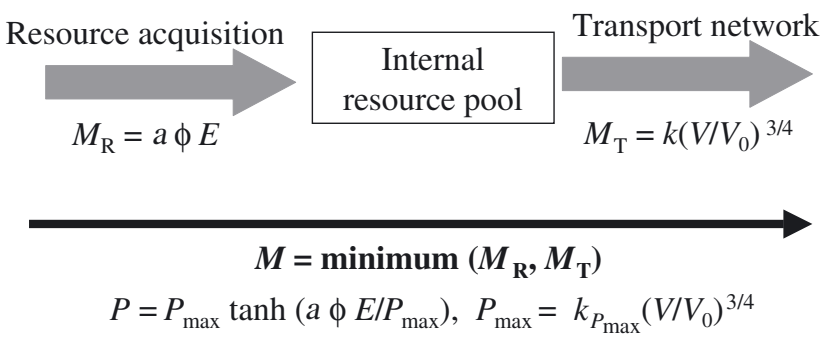

Fig. 1. Metabolic rate $(M)$ is determined by the minimum of the rate of supply of resources $\left(M_{R}\right)$ and the transport of the supply of resources $\left(M_{\mathrm{T}}\right)$ within the cell. When phytoplankton are limited by light, their photosynthetic rate is determined by light acquisition $\left(M_{\mathrm{R}}\right)$. Light absorption by unicellular organisms is size-dependent due to the package effect, which affects steady-state pigment concentrations and the effectiveness of the pigment at intercepting photons. When resources are not limiting and the internal resource pools are full, photosynthetic rate is determined by the transport of internal resources throughout the cell $\left(M_{\mathrm{T}}\right)$

ment concentration and cell size. The photons captured by photosynthetic pigments are used to generate reductant and, via an electrochemical $\mathrm{H}^{+}$gradient, ATP (Falkowski \& Raven 1997). If the supply of photons is insufficient to sustain the maximum photosynthetic rate, then photosynthesis is proportional to the rate of light acquisition. If the ATP and reductant pools are large enough to sustain the maximum photosynthetic rate, then the transport network that distributes the internal resources will ultimately limit the photosynthetic rate. We determine the consequences of this scheme on the size scaling of photosynthesis under light-limiting versus light-saturating conditions, and compare our theoretical predictions with experimental data.

How much pigment is required to maximize photosynthetic rate? Phytoplankton cells regulate their pigment concentration in response to a change in incident irradiance (Richardson et al. 1983, Falkowski \& LaRoche 1991, MacIntyre et al. 2002). To determine the size scaling of the resource driven photosynthetic rate, we need to know how photosynthetic rate and resource acquisition depend on cell size, and how the cell acclimates to the resource concentration in order to maximize its growth rate. It is therefore necessary to calculate the intracellular pigment concentration required to maximize photosynthesis for a given cell size at a given irradiance. This provides the basis for determining the size scaling of photosynthetic rates.

The intracellular pigment concentration required to maximize photosynthesis for a given cell size can be determined from a cost-benefit analysis of pigment. The benefit $(B)$ of the pigment is the fixed carbon generated from the photons captured by the pigments that make up the LHC. For any single cell, Eqs. (2) to (6) describe the collection of metabolically 
useful energy by the LHCs. For simplicity, we are operationally assigning all pigment within the cell to the LHCs and assume that chl $a$ is a dependable proxy for the total amount of pigment. This is a deliberately general description of the allocation of pigment; we are not distinguishing between changes in the ratio of Photosystem II to Photosystem I, the size or number of photosynthetic units, or the presence of non-photosynthetic pigments (Raven \& Kubler 2002).

The cost $(C)$ of the LHCs is the product of the quantum yield of photosynthesis $(\phi)$, the total pigment per cell $\left(c_{\mathrm{i}} V\right.$, mg chl a cell $\left.{ }^{-1}\right)$, the inverse of the lifetime of the pigment within the cell ( $\tau$ in hours) and its biosynthetic cost $\left(\xi, \mathrm{mg}\right.$ carbon $\left.\mathrm{mg} \operatorname{chl} a^{-1}\right)$. This cost function represents the synthesis and maintenance costs of the LHC, and is intended to account for the energetic cost of light acquisition. The LHCs of phytoplankton are genetically and phenotypically variable. Changes in the composition of the LHC alter the biosynthetic cost and lifetime of the LHC. Using the data available (Riper et al. 1979, Raven 1984, Goericke \& Welschmeyer 1992), we assume a constant $\tau$ of $1 \mathrm{~d}$, and use an average biosynthetic cost for chl a as calculated by Raven (1984).

Steady-state size scaling of photosynthesis over a light gradient with explict photoacclimation. The optimal intracellular pigment concentrations were determined by maximizing the net benefit $(N)$, which can be expressed as the difference between the carbon equivalents harvested $(B)$ and the cost $(C)$ of producing and maintaining the photosynthetic machinery necessary for harvesting light:

$$
N=B-C=P(E)-\frac{C_{\mathrm{i}} V \xi \phi}{\tau}
$$

Numerical optimization and other computations were performed using the statistical package $\mathrm{R}$ (Ihaka \& Gentleman 1996). We first computed optimal values of $C_{\mathrm{i}}$ as a function of $d$. These optimal intracellular pigment concentrations were then used to predict photosynthetic rates as a function of cell volume and irradiance.

Growth and photosynthetic rates are commonly reported after being normalized to carbon, chlorophyll content or cell number $\left(P^{\mathrm{C}}, P^{*}\right.$ and $P^{\text {cell }}$, respectively). This has the potential to cause considerable confusion, especially when comparing different size-scaling exponents. Under ideal conditions, $P^{\text {cell }}$ should have a size-scaling exponent of $3 / 4$, while $P^{\mathrm{C}}$ and $P^{*}$ are normalized by a measure of cell size and thus will have smaller size-scaling exponents. We expect that this exponent will be 1 less than the exponent of $P^{\text {cell }}$, because $\mathrm{C}$ cell ${ }^{-1} \propto V$ and $P^{\mathrm{C}} \propto P^{\text {cell }}$ $\times C$ cell $^{-1}$, but this is not always the case (Strath- mann 1967, Montagnes et al. 1994, Montagnes \& Franklin 2001). Cellular carbon content in phytoplankton is species-specific and varies with growth irradiance (Thompson et al. 1991). In the present study, we assume that carbon increases linearly with volume.

In accordance with previous experimental data (Agustí 1991, Finkel \& Irwin 2000, Finkel 2001), we view $C_{\mathrm{i}}$ and $P^{\text {cell }}$ as power-law functions of cell volume. The size-scaling exponents were estimated from linear regression. Over the size-ranges considered, model outputs are not always straight lines; thus, the range of cell volumes considered influences the estimate of the size-scaling exponent. We used the numerical model to produce data, which could have been obtained from experiments if our models had been perfectly correct, and then determine the size-scaling exponent from this simulated data in the same way we estimate exponents from laboratory data.

\section{RESULTS}

\section{Steady-state size scaling of photosynthesis over a light gradient}

The size dependence of the cellular photosynthetic rate depends on the steady-state irradiance and $E_{\mathrm{k}}$ (the irradiance where saturation occurs). At irradiances below $E_{\mathrm{k}}$, the size-dependence of photosynthetic rate is dominated by the size-dependence of light absorp-

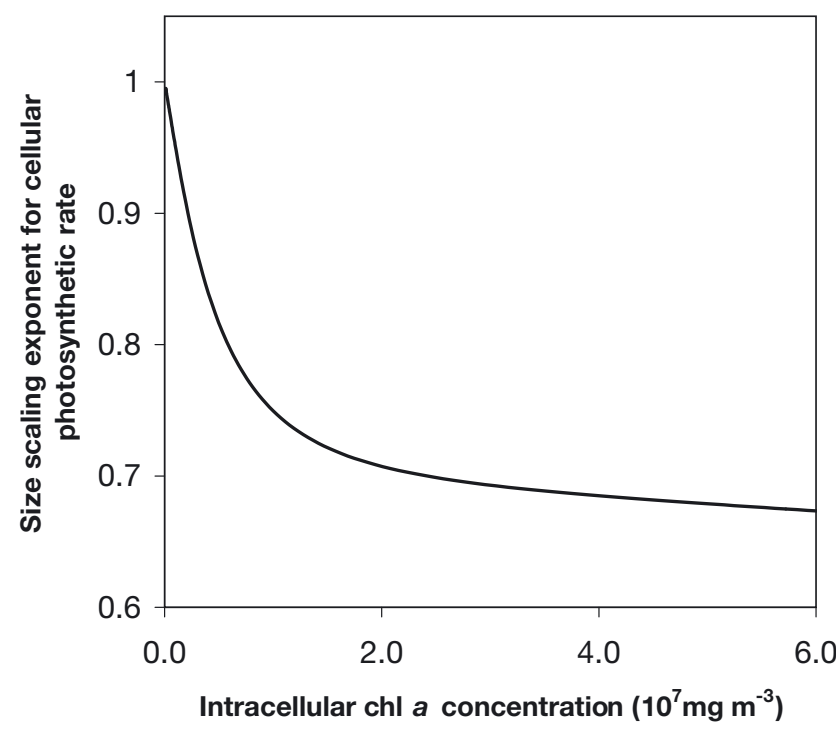

Fig. 2. Volume scaling exponent (b) associated with cellular photosynthetic rate $\left(P, \mathrm{mg} \mathrm{C} \mathrm{Cell}^{-1} \mathrm{~h}^{-1}\right)$ under low irradiance as a function of intracellular chl a concentrations $\left(C_{\mathrm{i}}, \mathrm{mg} \mathrm{chl} a\right.$ $\mathrm{m}^{-3}$ ). Intracellular $\mathrm{chl}$ a concentrations are treated as independent of cell volume 
tion and intracellular pigment concentration. At irradiances above $E_{\mathrm{k}}$, the size-dependence of photosynthesis is dictated by the size-dependence of the maximum photosynthetic rate, and is proportional to $V^{3 / 4}$ (Eq. 7). When we assume that $c_{\mathrm{i}}$ does not change with cell size, the model predicts that cellular light-limited photosynthetic rates scales from $V^{2 / 3}$ to $V^{1}$ as a function of $c_{\mathrm{i}}$ (Fig. 2 ). Experimental evidence shows that $C_{\mathrm{i}}$ does change with cell size, suggesting that we must determine how $C_{\mathrm{i}}$ changes as function of cell size and irradiance to have a realistic prediction of the size scaling of lightlimited photosynthetic rate.

\section{How much pigment is needed to reap the largest photosynthetic rate?}

Under sub-saturating irradiance, we can approximate the benefit of pigment as $B_{\mathrm{L}}=a \phi E$. We then determine the intracellular pigment concentration required to optimize the net benefit $\left(N=B_{\mathrm{L}}-C\right)$ per cell by differentiating with respect to $C_{\mathrm{i}}$ and setting the derivative equal to 0 :

$$
\begin{aligned}
\frac{\mathrm{d} N}{\mathrm{~d} c_{\mathrm{i}}}= & \frac{\pi}{6} d^{3}\left(a^{*} E-\xi / \tau\right)-\frac{\pi E a_{\mathrm{S}}^{*} d^{3}}{4 \rho^{3}} \times \\
& {\left[2\left(3+3 \rho+\rho^{2}\right) \mathrm{e}^{-2}-6+\rho^{2}\right]=0 }
\end{aligned}
$$

and after some straightforward algebra we obtain:

$$
6-3\left(2+2 \rho+\rho^{2}\right) \mathrm{e}^{-\rho}-\frac{\xi}{a^{*}{ }_{\mathrm{S}} E \tau} \rho^{3}=0
$$

Solving for $C_{\mathrm{i}}$ we find:

$$
C_{\mathrm{i}}=\frac{f(z)}{a_{\mathrm{s}}^{*} d} \propto \frac{1}{d}
$$

where $f$ is a proportionality factor evaluated numerically and depending only on $z$ defined as:

$$
z=\frac{a^{*}{ }_{\mathrm{S}} E \tau}{\xi}
$$

The magnitude of $C_{\mathrm{i}}$ depends on $z$, but the size-scaling exponent is independent of $z$. Our result, $C_{\mathrm{i}} \propto 1 / \mathrm{d}$ (Eqs. 11 \& 12) is in excellent agreement with laboratory measurements of light-limited phytoplankton cultures (Fig. 3).

The size-dependence of the optimal intracellular chlorophyll concentrations at all irradiances can be determined using numerical optimizations to maximize photosynthetic rate based on Eqs. (2) to (8). As expected, under optimal intracellular chlorophyll concentrations, cellular photosynthetic rate, regardless of cell size, is a saturating function of irradiance. Our computations, in close agreement with measured data, show that intracellular pigment concentration increases with $E$ under very low $E_{\text {, and above } E_{\mathrm{k}}}$ decreases with $E$ (Fig. 4). Different species have different intracellular pigment concentrations based on species- and class-specific differences in cell size,

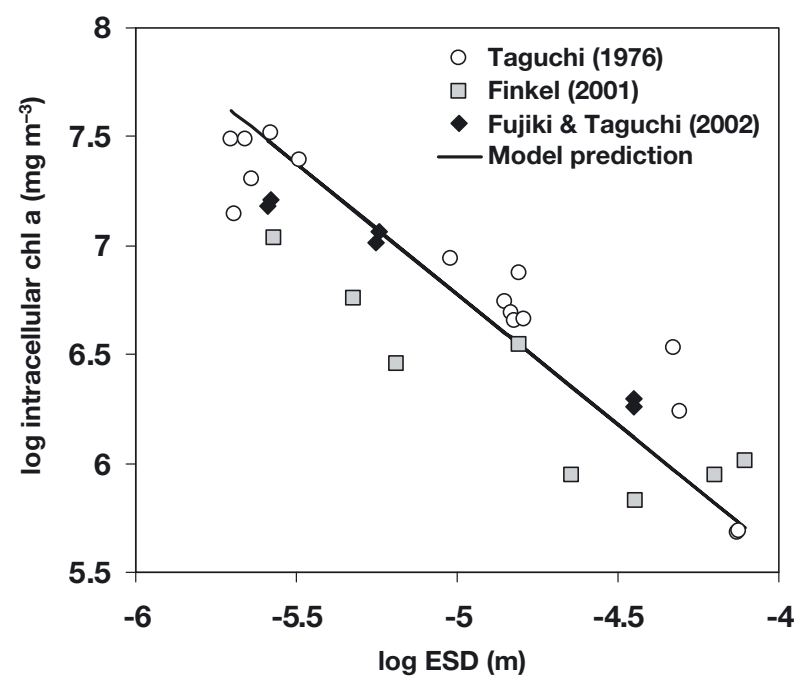

Fig. 3. Intracellular chl a concentration $\left(c_{\mathrm{i}}, \mathrm{mg} \mathrm{chl} a \mathrm{~m}^{-3}\right)$ as a function of equivalent spherical diameter (ESD, m) in 30 different species of light-limited, nutrient-saturated diatom cultures. Volume scaling exponent calculated from reduced major axis regression on the experimental data is $-1.01 \pm 0.15$, in agreement with our theoretical prediction $(-1)$

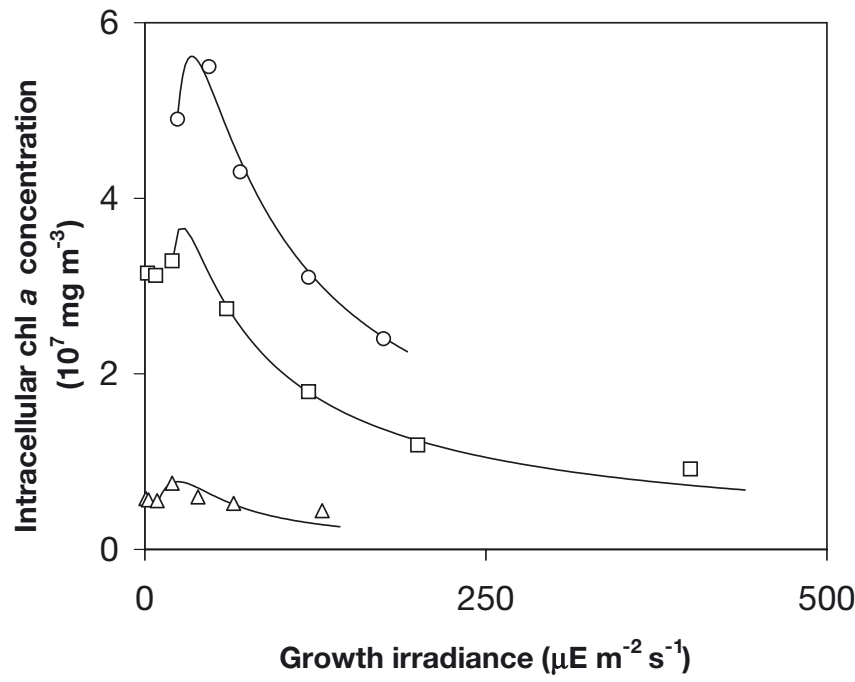

Fig. 4. Comparison of experimentally derived and modeled intracellular chl a concentration $\left(C_{\mathrm{i}}, \mathrm{mg} \mathrm{chl} \mathrm{a} \mathrm{m}^{-3}\right)$ as a function of growth irradiance $\left(E, \mu \mathrm{E} \mathrm{m} \mathrm{m}^{-2} \mathrm{~s}^{-1}\right)$. The theoretical model (solid lines) is the optimal $C_{\mathrm{i}}$ for each species: Skeletonema costatum $(\triangle)$ and Dunaliella tertiolecta $(\square)$ from (Falkowski \& Owens 1980), and Emiliania huxleyi (O) from (Muggli \& Harrison 1996). The models for different species differ from one another only by having different values of $a^{*}{ }_{s}, k_{P \max } \tau$ and $\xi$ (see Table 1 for definitions). Values of these constants were selected by minimizing the sum of squared deviations between the data points and the predictions of $C_{\mathrm{i}}$ at the corresponding irradiance 
$a^{*}{ }_{s}$, and the cost and turnover time of the different types of LHC. The increase in $C_{\mathrm{i}}$ with increasing irradiance at low $E$, despite corresponding increases in the package effect, is due to an increase in marginal benefit with irradiance. As irradiances become saturating, harvesting more photons provides no additional net benefit; therefore, intracellular pigment concentration decreases with irradiance and the package effect decreases. Given that the maximum cellular photosynthetic rate is proportional to $V^{3 / 4}$, our model predicts that the optimal $C_{\mathrm{i}}$ is proportional to $V^{-1 / 4}$ for $E \geq E_{\mathrm{k}}$, and is proportional to $V^{-\frac{1}{3}}$ for $E<E_{\mathrm{k}}$.

The theoretical predictions for the size scaling of intracellular pigment concentration compare well with Fujiti \& Taguchi's (2002) experimental results on phytoplankton cultures. In this study, 6 different species, representing 3 different taxonomic groups, were grown over a range of irradiances. We calculated the size scaling of chl a content per cell, chl a cell ${ }^{-1}=K_{\mathrm{chl}}$ $V / V_{0}$, for each irradiance by multiplying $c_{\mathrm{i}}$ by cell volume. The results show that under saturating irradiance, the size-scaling exponent of cellular chl a content with cell volume is $3 / 4$, in agreement with our theoretical prediction $\left(V^{-1 / 4} \times V=V^{3 / 4}\right)$. As growth irradiance decreases, the size scaling of chlorophyll content decreases towards $0.71 \pm 0.05$ (95\% confidence interval), in agreement with our theoretically predicted value under light limitation (Fig. 5).

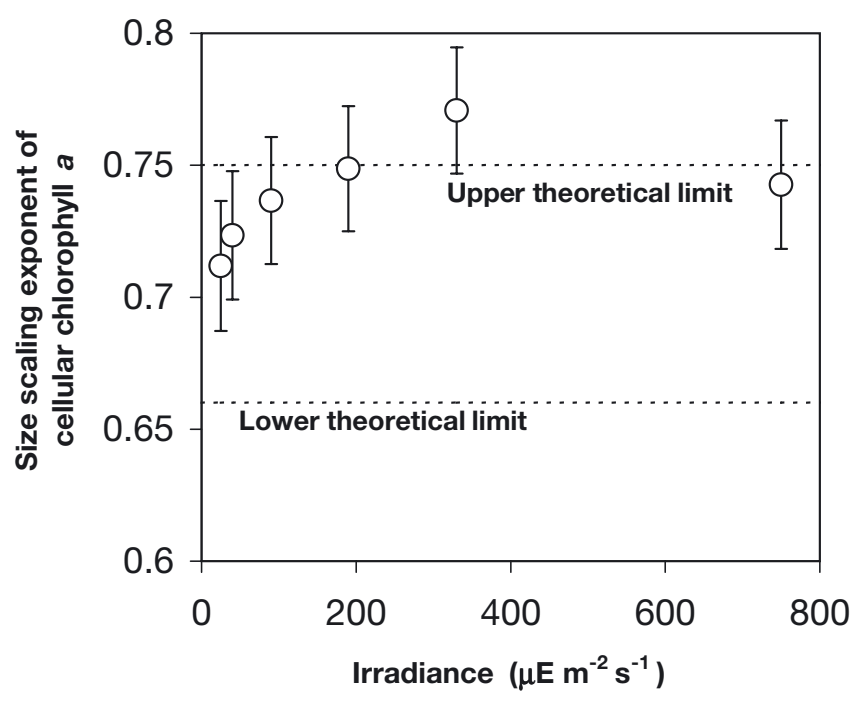

Fig. 5. Comparison between the size scaling exponent $(b)$ associated with chl a per cell (mg chl $a$ cell $\left.^{-1}\right)$ as a function of steady-state irradiance $\left(E, \mu E \mathrm{~m}^{-2} \mathrm{~s}^{-1}\right)$ as predicted by theory (dotted lines) and observed in experimental cultures (symbols, $\pm 1 \mathrm{SE}$ ). The size-scaling exponent of intracellular pigment content decreases with increasing light limitation. Open circles from (Fujiki \& Taguchi 2002). As light becomes limiting, the size-scaling exponent decreases from a theoretical maximum of 0.75 to a theoretical minimum of 0.67
The parameters in $z$ (Eq. 12) can change the intercept, but not the slope of $\log c_{\mathrm{i}}$ versus $\log d$. This is important as different taxonomic groups, under different growth conditions, can have different values of $a^{*}{ }^{*}, \xi$, and $\tau$, which will alter the value of $z$. Changes in $z$ that are correlated with cell size will appear to alter the slope of $\log c_{\mathrm{i}}$ versus $\log d$. For example, many of the largest cells are not spherical, but instead resemble very long and narrow, or flat and squat, cylinders. A systematic shift in shape, from spherical cells to cylinders, with increasing cell size will reduce the effect of self-shading on the size scaling of photosynthesis and growth (Kirk 1976, 1994). Thus, a change in shape can reduce the package effect and mitigate the potential reduction in the size-scaling exponent of cellular pigment concentration and growth rates. This means that it is important to compare organisms with similar pigment composition under similar growth conditions when calculating and comparing the slope of $\log C_{\mathrm{i}}$ versus $\log d$. Speciesspecific changes in the parameters in $z$, and changes in cell shape (aspect ratio), and subtle changes in growth conditions, are likely responsible for much of the variability in the experimental data presented in Figs. 3 to 5 .

\section{Steady-state size scaling of photosynthesis over a light gradient with explicit photoacclimation}

The relationship between optimal $C_{\mathrm{i}}$ and cell size can be used to determine photosynthetic rate as a function of cell size, and the resultant size-scaling exponent. Under sub-saturating irradiance, photosynthetic rate is a function of the rate of light acquisition, and therefore scales with cell volume with a $2 / 3$ exponent. Under saturating irradiance, growth is a function of the size-dependent transport network and therefore scales with cell volume with a $3 / 4$ exponent. These results are in good agreement with experimental work on phytoplankton (Table 2). These results should not be applied to organisms that are $<1 \mu \mathrm{m}$ in diameter because non-scalable components such as a minimum DNA content can result in radical changes in cellular composition (Raven 1994). At intermediate irradiances between extreme light limitation and saturation, photosynthetic rates will scale with cell volume with an exponent somewhere between $2 / 3$ and $3 / 4$. This is because $E_{\mathrm{k}}$, the irradiance that characterizes the transition from light limitation to light saturation, is size-dependent. Commonly, $E_{\mathrm{k}}$ is defined as $P_{\max } /(a \phi)$ at low $E$. This means that $E_{\mathrm{k}}$ is affected by both the size-dependence of the transport network $\left(P_{\max }=k V^{3 / 4}\right)$ and the size-dependence of light acquisition $\left(a=a^{*} c_{\mathrm{i}} V\right)$. Numerical calculations show that 
Table 2. Size-scaling exponent as a function of cell volume of cellular photosynthetic rate $\left(P^{\text {cell }}, \mathrm{mg} \mathrm{C}^{\mathrm{C}} \mathrm{cell}^{-1} \mathrm{~h}^{-1}\right)$ and cellular chl a content (mg chl a cell $\left.{ }^{-1}\right)$ under light-limiting $\left(25 \mu \mathrm{E} \mathrm{m}^{-2} \mathrm{~s}^{-1}\right)$ and -saturating conditions. Numbers in parentheses are $2 \mathrm{SE}$

\begin{tabular}{|c|c|c|c|c|c|c|}
\hline & \multicolumn{3}{|c|}{$-P^{\text {cell }}$} & \multicolumn{3}{|c|}{ Chl $a$ cell $^{-1}$} \\
\hline & Theory & Experiment & Source & Theory & Experiment & Source \\
\hline Light limitation & 0.67 & $0.60(0.08)^{\mathrm{a}}$ & $\begin{array}{l}\text { Taguchi (1976), } \\
\text { Finkel (2001) }\end{array}$ & 0.67 & $0.70(0.03)$ & $\begin{array}{l}\text { Taguchi (1976), Finkel (2001) } \\
\text { Fujiki \& Taguchi (2002) }\end{array}$ \\
\hline Light saturation & 0.75 & $0.79(0.04)$ & $\begin{array}{l}\text { Fujiki \& Taguchi } \\
(2002)\end{array}$ & 0.75 & $0.75(0.02)$ & $\begin{array}{l}\text { Fujiki \& Taguchi } \\
(2002)\end{array}$ \\
\hline
\end{tabular}

the volume size scaling of $E_{\mathrm{k}} \propto V^{1 / 12}$. This means that there are light intensities where photoacclimated small cells will be saturated for light, while larger cells are limited for light.

\section{DISCUSSION}

As organisms increase in size, their mass-specific metabolic rates decrease due to geometric constraints (West et al. 1997, Banavar et al. 2002). Specifically, larger organisms must allocate a larger proportion of their mass to their resource transportation systems or suffer a reduction in their mass-specific metabolic rates. Generally, the proportion of biomass allocated to transport systems is not strongly correlated with body size. As a consequence, under optimal growth conditions when resource supply matches demand, metabolic rate scales to the $3 / 4$ power of biomass (Banavar et al. 2002).

Under resource-limiting conditions, organisms must allocate an increasing proportion of their internal resources and total biomass towards resource acquisition. A size-dependence in resource gathering abilities can counter, or augment, the geometric constraints that cause the $3 / 4$ size scaling of metabolic rates. An increase in the ability to harvest resources with body size might lead to an increase in the size-scaling exponent of individual based metabolic rate, although constraints imposed by the demands of transportation networks will limit this effect. A decrease in the ability to harvest resources with body size will cause a decrease in the size-scaling exponent of individual based metabolic rate because there is no way for a transportation network to compensate for unavailable resources. Light acquisition by unicellular phytoplankton is just one example of the size-dependence of the ability to harvest resources due to geometric constraints.

Under light-limiting conditions, the rate of photon absorption determines the photosynthetic rate (Kiefer \& Mitchell 1983, Falkowski et al. 1985). Light absorp- tion in unicellular photoautotrophs depends on the incident irradiance, cell volume and shape, pigment concentration, composition, and distribution within the cell (Kirk 1994). Assuming optimal pigment composition and distribution, a cell can gather more photons only by increasing its pigment concentration. Under light-saturating conditions, in the absence of any package effect, pigment scales with body mass with a $3 / 4$ exponent (Fig. 5), not only for phytoplankton but also for higher plants (Niklas \& Enquist 2001). As Niklas \& Enquist (2001) point out, this is precisely what is expected if natural selection adjusts pigment concentration to maximize metabolic rate. In other words, an organism should not harvest more energy than it can effectively use.

Photoautotrophs generally increase their pigment concentration in response to decreasing growth irradiance. Phytoplankton cellular pigment concentrations can increase as much as 5- to 9-fold in response to decreases in irradiance, in a matter of hours to days (Falkowski \& Owens 1980, Ley \& Mauzerall 1982, Post et al. 1984, Prezelin et al. 1986, Cullen \& Lewis 1988, Falkowski \& LaRoche 1991). Pigment responses to changes in growth irradiance are less dramatic in higher plants, although increases of 2- to 3-fold are not uncommon (Evans \& Poorter 2001). This is not surprising given that land plants generally experience higher photon flux densities, and spend their whole lives in one location. Phytoplankton cells are continually mixed throughout the water column, and have the ability to acclimate to a wide range of light intensities. Due to the cost of the LHC there is both a size- and irradiance-dependent limit to pigment acclimation in response to irradiance.

The maximum pigment concentration or cell size that can be maintained at a given irradiance is governed by the cost of the LHC and the diminishing returns associated with the increasing internal selfshading of pigment that leads to the decrease in the pigment-specific light absorption coefficient. The package effect depends on the product of the intra- 
cellular pigment concentration and cell diameter $\left(c_{\mathrm{i}} d\right.$, Eqs. 3 to 6). If $c_{\mathrm{i}}$ is constant, the package effect increases with diameter, and light-limited pigment-specific light acquisition drops rapidly with cell volume. As a result, larger phytoplankton cannot afford to maintain the same intracellular pigment concentrations as smaller cells. This accounts for the inverse relationship between $c_{\mathrm{i}}$ and $d$ reported for phytoplankton (Agustí 1991, Finkel 2001). Consequently, the decrease in cellular photosynthesis with decreasing irradiance is sizedependent with an exponent other than $3 / 4$.

Other forms of resource limitation may also alter the $3 / 4$ size scaling of metabolic rates if the acquisition of the resource is size-dependent. For example, nutrient limitation may also cause anomalous size scaling of metabolic rates in a variety of organisms, including phytoplankton (Eppley et al. 1969, Gavis 1976, Hudson \& Morel 1993, Hein et al. 1995). Consider nutrient uptake $\left(U\right.$, nutrient cell $\left.{ }^{-1} \mathrm{~h}^{-1}\right)$ by a phytoplankton cell, which depends on nutrient diffusion (Pasciak \& Gavis 1974):

$$
U \propto 4 \pi d D \Delta C
$$

where $D$ is the diffusion coefficient of the nutrient in question, and $\Delta C$ is the concentration gradient of the nutrient from the cell surface to the concentration in the bulk media. In a Droop-type model, $U$ is a function of growth rate $\left(\mu, h^{-1}\right)$ and the cellular quota for that nutrient $\left(q\right.$, nutrient cell $\left.^{-1}\right)$ :

$$
U=\mu q
$$

where $q \propto V^{3 / 4}$ (Stolte \& Riegman 1995). At equilibrium, we can assume that these 2 expressions for uptake are equal. Rearranging Eqs. (13) \& (14) we can solve for the size dependence of the growth rate; $\mu \propto V^{-5 / 12}$. Future models should also consider the dependence of uptake and cell quota on nutrient concentrations in the bulk media (nutrient acclimation). More research is needed to determine whether size-dependent resource acquisition for other limiting resources, and in other organisms, causes similar changes to the size scaling of metabolic rates.

\section{CONCLUSIONS}

The $3 / 4$ rule of metabolic rates is a key concept in macroecology (Brown 1995). It has been suggested that the $3 / 4$ rule is the key to understanding not only metabolic rates but also fundamental ecological and evolutionary patterns in abundance and diversity (Rosenweig 1995, Whitfield 2001). However, there are many reported examples where the $3 / 4$ rule does not apply. We present a model that demonstrates that resource limitation causes quantifiable, predictable deviations from the $3 / 4$ rule.
Specifically, we demonstrate that when irradiance limits photosynthetic rates in phytoplankton, light acquisition alters the size scaling of photosynthesis. In the absence of photoacclimation, the size scaling of cellular photosynthetic rate is proportional to $V^{b}$, where $b$ ranges from $2 / 3$ to 1 depending on the intracellular pigment concentration, irradiance and size range considered. In actuality, phytoplankton acclimate to their incident irradiance via changes in intracellular pigment concentration in order to maximize their cellular photosynthetic rate as a function of irradiance. There is a size-dependence associated with the ability of phytoplankton cells to acclimate to decreases in irradiance via their intracellular pigment concentrations due to the package effect. As a consequence, larger phytoplankton cells support lower maximum intracellular pigment concentrations, and require higher irradiances to reach their maximum cellular photosynthetic rate. This suggests that smaller phytoplankton cells are at an advantage over larger cells under steady-state light-limiting conditions.

Incorporating pigment acclimation into our model allows us to predict the irradiance and size-dependence of intracellular pigment concentration, and the resultant change in the size scaling of exponent associated with cellular photosynthetic rate. We predict that the size scaling of cellular photosynthesis is proportional to $V^{3 / 4}$ under light-saturating conditions and decreases towards $V^{2 / 3}$ as light becomes limiting, in good agreement with experimental data. This example suggests that other forms of resource limitation in other types of organisms may also alter the size scaling of metabolic rates.

Acknowledgements. We thank R. Armstrong, S. Tozzi, E. Litchman, A. Quigg, H. Stevens, J. Raven, M. Gorbunov, J. Huisman, P. Morin, and P. Falkowski for many constructive comments. This work was supported by an NSF Biocomplexity grant (OCE-0084032), ONR HyCode Program (N0014-990196), and an NSERC post-doctoral fellowship to A.J.I.

\section{LITERATURE CITED}

Agustí S (1991) Allometric scaling of light absorption and scattering by phytoplankton cells. Can J Fish Aquat Sci 48(5):763-767

Banavar JR, Damuth J, Maritan A, Rinaldo A (2002) Supplydemand balance and metabolic scaling. Proc Natl Acad Sci USA 99(16):10506-10509

Berner T, Dubinsky Z, Wyman K, Falkowski PG (1989) Photoadaptation and the 'package effect' in Dunaliella tertiolecta (Chlorophyceae). J Phycol 25:70-78

Berry J, Bjorkman O (1980) Photosynthetic response and adaptation to temperature in higher plants. Annu Rev Plant Physiol 31:491-543

Bonner JT (1988) The evolution of complexity by means of natural selection. Princeton University Press, Princeton, NJ

Brown JH (1995) Macroecology. University of Chicago Press, Chicago 
Chisholm SW (1992) Phytoplankton size. In: Falkowski PG, Woodhead AD (eds) Primary productivity and biogeochemical cycles in the sea. Plenum Press, New York, p 213-237

Cullen JJ, Lewis MR (1988) The kinetics of algal photoadaptation in the context of vertical mixing. J Plankton Res 10(5):1039-1063

Cullen JJ, Reid FMH, Stewart E (1982) Phytoplankton in the surface and chlorophyll maximum off southern California in August, 1978. J Plankton Res 4(3):665-694

Cullen JJ, Geider RJ, Ishizaka J, Kiefer DA, Marra J, Sakshaug E, Raven JA (1993) Toward a general description of phytoplankton growth for biogeochemical models. In: Evans GT, Fasham MJR (eds) Towards a model of ocean biogeochemical processes, Vol 10. Springer-Verlag, Berlin, p 153-176

Eppley RW, Rogers JN, McCarthy JJ (1969) Half-saturation constants for uptake of nitrate and ammonium by marine phytoplankton. Limnol Oceanogr 14:912-920

Evans JR, Poorter H (2001) Photosynthetic acclimation of plants to growth irradiance: the relative importance of specific leaf area and nitrogen partitioning in maximizing carbon gain. Plant Cell Environ 24:755-767

Falkowski PG (1994) The role of phytoplankton photosynthesis in global biogeochemical cycles. Photosynth Res 39: 235-258

Falkowski PG, LaRoche J (1991) Acclimation to spectral irradiance in algae. J Phycol 27:8-14

Falkowski P, Owens TG (1980) Light-shade adaptation. Plant Physiol 66:592-595

Falkowski P, Raven JA (1997) Aquatic photosynthesis. Blackwell, Malden, MA

Falkowski PG, Dubinsky Z, Wyman K (1985) Growth-irradiance relationships in phytoplankton. Limnol Oceanogr 30(2): 311-321

Finkel ZV (2001) Light absorption and size scaling of lightlimited metabolism in marine diatoms. Limnol Oceanogr 46(1):86-94

Finkel ZV, Irwin AJ (2000) Modeling size-dependent photosynthesis: light absorption and the allometric rule. J Theor Biol 204(3):361-369

Fujiki T, Taguchi S (2002) Variability in chlorophyll a specific absorption coefficient in marine phytoplankton as a function of cell size and irradiance. J Plankton Res 24(9):859-874

Gavis J (1976) Munk and Riley revisited: nutrient diffusion transport and rates of phytoplankton growth. J Mar Res 34:161-179

Gillooly JF, Brown JH, West GB, Savage VM, Charnov EL (2001) Effects of size and temperature on metabolic rate. Science 293(5538):2248-2251

Goericke R, Welschmeyer NA (1992) Pigment turnover in the marine diatom Thalassiosira weissflogii. II. The ${ }^{14} \mathrm{CO}_{2}$ labeling kinetics of carotenoids. J Phycol 28:507-517

Gould SJ (1966) Allometry and size in ontogeny and phylogeny. Biol Rev 41:587-640

Hein M, Folager Pedersen M, Sand-Jensen K (1995) Sizedependent nitrogen uptake in micro- and macroalgae. Mar Ecol Prog Ser 118:247-253

Hemmingsen AM (1960) Energy metabolism as related to body size and respiratory surfaces, and its evolution. Rep Steno Mem Hospital 9(2):15-22

Hudson RJM, Morel FMM (1993) Trace metal transport by marine microorganisms: implications of metal coordination kinetics. Deep-Sea Res 40(1):129-150

Ihaka R, Gentleman R (1996) R: a language for data analysis and graphics. J Comput Graph Stat 5:299-314

Jones RI (1978) Adaptations to fluctuating irradiance by nat- ural phytoplankton communities. Limnol Oceanogr 23(5): 920-926

Kerr SR, Dickie LM (2001) The biomass spectrum: a predatorprey theory of aquatic production. Columbia University Press, New York

Kiefer DA, Mitchell BG (1983) A simple, steady state description of phytoplankton growth based on absorption cross section and quantum efficiency. Limnol Oceanogr 28(4): $770-776$

Kirk JTO (1976) A theoretical analysis of the contribution of algal cells to the attenuation of light within natural waters. III. Cylindrical and spheroidal cells. New Phytol 77:341-358

Kirk JTO (1994) Light and photosynthesis in aquatic ecosystems. Cambridge University Press, Cambridge

Kleiber M (1947) Body size and metabolic rate. Physiol Rev 27:511-541

Kleiber M (1961) The fire of life: an introduction to animal energetics. John Wiley \& Sons, New York

Ley AC, Mauzerall DC (1982) Absolute absorption crosssections for photosystem II and the minimum quantum requirement for photosynthesis in Chlorella vulgaris. Biochim Biophys Acta 680:95-106

MacIntyre HL, Kana TM, Anning J, Geider R (2002) Photoacclimation of photosynthesis irradiance response curves and photosynthetic pigments in microalgae and cyanobacteria. J Phycol 38:17-38

Montagnes DJS, Franklin DJ (2001) Effect of temperature on diatom volume, growth rate, and carbon and nitrogen content: reconsidering some paradigms. Limnol Oceanogr 46(8):2008-2018

Montagnes DJS, Berges JA, Harrison PJ, Taylor FJR (1994) Estimating carbon, nitrogen, protein, and chlorophyll a from volume in marine phytoplankton. Limnol Oceanogr 39:1044-1060

Morel A, Bricaud A (1981) Theoretical results concerning light absorption in a discrete medium, and application to specific absorption of phytoplankton. Deep-Sea Res 1 28A(11):1375-1393

Morris I, Glover HE (1974) Questions on the mechanism of temperature adaptation in marine phytoplankton. Mar Biol 24:147-154

Muggli DL, Harrison PJ (1996) Effects of nitrogen source on the physiology and metal nutrition of Emiliania huxleyi grown under different iron and light conditions. Mar Ecol Prog Ser 130:255-267

Niklas KJ, Enquist BJ (2001) Invariant scaling relationships for interspecific plant biomass production rates and body size. Proc Natl Acad Sci USA 98(5):2922-2927

Pasciak WJ, Gavis J (1974) Transport limitation of nutrient uptake in phytoplankton. Limnol Oceanogr 19(6):881-888

Peters RH (1983) The ecological implications of body size, Cambridge University Press, Cambridge

Post AF, Dubinsky Z, Wyman K, Falkowski PG (1984) Kinetics of light-intensity adaptation in a marine planktonic diatom. Mar Biol 83:231-238

Prezelin B, Samuelsson G, Matlick HA (1986) Nutrientdependent kinetics of photosynthesis parameters and photoinhibition of photosystem II during high light photoadaptation in Gonyaulax polyedra. Mar Biol 93:1-12

Raven JA (1984) A cost-benefit analysis of photon absorption by photosynthetic unicells. New Phytol 98:593-625

Raven JA (1994) Why are there no picoplanktonic $\mathrm{O}_{2}$ evolvers with volumes less than $10^{-19} \mathrm{~m}^{3}$ ? J Plankton Res 16:565-580

Raven JA (1997) The vacuole: a cost-benefit analysis. In: Leigh RA, Sanders D (eds) The plant vacuole, Vol 25. Academic Press, San Diego, p 59-82

Raven JA, Kubler JE (2002) New light on the scaling of meta- 
bolic rate with the size of algae. J Phycol 38:11-16

Richardson K, Beardall J, Raven JA (1983) Adaptation of unicellular algae to irradiance: an analysis of strategies. New Phytol 93:157-191

Riper DM, Owens TG, Falkowski P (1979) Chlorophyll turnover in Skeletonema costatum, a marine plankton diatom. Plant Physiol 64:49-54

Rosenweig ML (1995) Species diversity in space and time. Cambridge University Press, Cambridge

Round FE, Crawford RM, Mann DG (1990) The diatoms: biology and morphology of the genera. Cambridge University Press, Cambridge

Schlesinger DA, Molot LA, Shuter BG (1981) Specific growth rates of freshwater algae in relation to cell size and light intensity. Can J Fish Aquat Sci 38: 1052-1058

Sommer U (1989) Maximal growth rates of Antarctic phytoplankton: only weak dependence on cell size. Limnol Oceanogr 34(6):1109-1112

Stolte W, Riegman R (1995) The effect of phytoplankton cell

Editorial responsibility: Andrea Belgrano,

Santa Fe, New Mexico, USA size on transient state nitrate and ammonium uptake kinetics. Microbiology 141:1221-1229

Strathmann RR (1967) Estimating the organic carbon content of phytoplankton from cell volume or plasma volume. Limnol Oceangr 12:411-418

Taguchi S (1976) Relationship between photosynthesis and cell size of marine diatoms. J Phycol 12(2):185-189

Thompson PA, Harrison PJ, Parslow JS (1991) Influence of irradiance on cell volume and carbon quota for ten species of marine phytoplankton. J Phycol 27:351-360

Trammer J (2002) Power formula for Cope's rule. Evol Ecol Res 4:147-153

Welschmeyer NA, Lorenzen CJ (1981) Chlorophyll-specific photosynthesis and quantum efficiency at subsaturating light intensities. J Phycol 17:283-293

West GB, Brown JH, Enquist BJ (1997) A general model for the origin of allometric scaling laws in biology. Science 276(5309):122-126

Whitfield J (2001) All creatures great and small. Nature 413: 342-344

Submitted: April 16, 2003; Accepted: January 27, 2004

Proofs received from author(s): April 18, 2004 